\title{
Acompanhantes terapêuticos na Grande Vitória, Espírito Santo, Brasil: quem são o o que farem?
}

Kelly Guimarães Tristão(a)

Luziane Zacché Avellar (b)

Tristão KG, Avellar LZ. Therapeutic attendants in the Greater Vitória, Espírito Santo State, Brazil: who are they and what do they do? Interface (Botucatu). 2014; 18(50):533-44.

Therapeutic accompaniment (TA) is a tool that enables expansion and linkage of a mental health care network. The aim was to identify who the therapeutic attendantsare, in the Greater Vitória, Espírito Santo (ES), Brazil, and the characteristics of this practice. Ten partially structured interviews were conducted with professionals who were using or had used TA in public and/or private services. The data obtained were analyzed using thematic analysis. The results showed that the therapeutic attendantsin the Greater Vitória were mostly female psychology students, with various theoretical approaches, whose training in TA had not be accomplished through a course in this field. TA practices in the Greater Vitória are characterized by little use of accompaniment teams, use of pair work, time flexibility, interventions in the street and friendship.

Keywords: Mental health.

Deinstitutionalization. Mental health services. Therapeutic accompaniment.
O Acompanhamento Terapêutico (AT) é uma ferramenta que possibilita uma ampliação e articulação da rede de saúde mental. Com objetivo de conhecer quem são os acompanhantes terapêuticos (ats) da Grande Vitória/ES, Brasil, e as características dessa prática, foram realizadas dez entrevistas parcialmente estruturadas com profissionais que utilizam, ou utilizaram, o Acompanhamento Terapêutico na rede pública e/ou privada. Os dados obtidos foram analisados a partir da Análise Temática. Os resultados apontam que os ats da Grande Vitória são, em maioria: estudantes de psicologia do sexo feminino, de abordagens teóricas variadas, e cuja formação em Acompanhamento Terapêutico não é realizada a partir de curso da área. A prática de AT na Grande Vitória é caracterizada: pela pouca inserção em equipes de acompanhantes, atuação em dupla, flexibilidade do tempo, por intervenções realizadas na rua e pelo afeto.

Palavras-chave: Saúde mental.

Desinstitucionalização. Serviços de saúde mental. Acompanhamento Terapêutico. $(\mathrm{a}, \mathrm{b})$ Programa de Pós-Graduação em Psicologia, Universidade Federal do Espírito Santo. Centro de Ciências Humanas e Naturais. Av. Fernando Ferrari, s/n, Goiabeiras. Vitória, ES, Brasil. 29075-910 kgtristao@hotmail. com; luzianeavellar@ yahoo.com.br 


\section{Introdução}

\section{A emergência do Acompanhamento Terapêutico}

O processo de desinstitucionalização pautado nos pressupostos da luta antimanicomial, iniciada no Brasil com o Movimento da Reforma Psiquiátrica, na década de 1970, vem sendo marcado por esforços no que tange à criação de estruturas substitutivas aos manicômios ${ }^{1}$. Com a redução dos leitos psiquiátricos e a alta de pacientes que se encontravam em internações de longa duração, fez-se necessária a criação de recursos alternativos à internação, que viabilizassem a rede de assistência a esses sujeitos ${ }^{2}$. Desta forma, os Centros de Atenção Psicossocial (CAPS), Serviços Residenciais Terapêuticos e do Programa De Volta pra $\mathrm{Casa}^{3}$ tornaram-se recursos importantes para a viabilidade de tal processo ${ }^{4}$.

Entretanto, há uma problemática no funcionamento dessa rede: o risco de reproduzir, em tais serviços, as características manicomiais de tutela, segregação e isolamento ${ }^{1,5}$. Amorim e Dimenstein ${ }^{5}$ apontam para a necessidade de políticas públicas que promovam a articulação da vida desses sujeitos com os espaços sociais, onde seja possível, a cada sujeito, circular e construir novas possibilidades de enfrentamento às situações do cotidiano.

Podemos pensar o Acompanhamento Terapêutico como uma prática possível de se inserir nesse contexto, por se tratar de uma clínica que tenta articular a relação da loucura com a cidade sendo, portanto, uma prática inclusiva, sobretudo por auxiliar no desenvolvimento dos processos de autonomia e da construção de cidadania dos portadores de distúrbios psiquiátricos ${ }^{6,7}$. Sendo essa prática pertinente ao panorama de ampliação da rede ${ }^{(c)}$ de assistência em saúde mental, pretende-se conhecer as características do AT na Grande Vitória. Para isto, iremos fazer um breve resgate histórico.

\section{A construção do Acompanhamento Terapêutico}

O Acompanhamento Terapêutico, pode-se dizer, teve seu início ligado ao movimento da Reforma Psiquiátrica ${ }^{7-10}$. O objetivo principal era aproximar-se do paciente no que se refere aos aspectos do cotidiano, por meio de visitas a sua casa, reunindo-se com amigos, acompanhando-o a médicos etc. Nesse momento, o trabalho do acompanhante terapêutico era basicamente assistencial ${ }^{10}$, e era denominado, primeiramente, "auxiliar psiquiátrico" ou "atendente psiquiátrico", mais tarde, evoluiu para "amigo qualificado"11-13.

A partir da mudança desse exercício profissional para experiência clínica e terapêutica, o termo "amigo qualificado" foi substituído por "acompanhante terapêutico". O termo "amigo qualificado" apontava para um elemento muito afetivo do vínculo, ${ }^{9,14}$, por outro lado, o termo acompanhante terapêutico começou a ressaltar o componente terapêutico e profissional ${ }^{10,15,16}$.

No Brasil, a prática se iniciou mais especificamente em Porto Alegre, São Paulo e Rio de Janeiro. A Clínica Pinel, em Porto Alegre, foi o primeiro lugar a ter a função de atendente psiquiátrico ${ }^{12,17,18}$, e a Clínica de Vila Pinheiros, RJ, foi a primeira a ter a função do "auxiliar psiquiátrico" no tratamento de pacientes psicóticos ${ }^{9,19,20}$. Segundo Barreto ${ }^{20}$ e Azevedo e Dimenstein ${ }^{21}$, após o fechamento das comunidades terapêuticas no Brasil, esses profissionais continuaram a ser solicitados por aqueles que procuravam alternativas à internação; desta forma, a prática foi se solidificando e os profissionais necessitando de especialização até serem reconhecidos como acompanhantes terapêuticos. (c) Atualmente, a rede de serviços em Saúde Mental na Grande Vitória é composta por quatro CAPS II (Saúde Mental), um CAPS i e três CAPS ad (sendo um CAPS III e dois CAPS II), Serviços de Saúde com internação e 17 Serviços Residenciais Terapêuticos. Disponível em: http://www.es.gov. br/Cidadao/Paginas/ dependentes_quimicos. aspx 
No Espírito Santo, a experiência de Acompanhamento Terapêutico iniciou-se no CAPS Ilha de Santa Maria, na cidade de Vitória, e no antigo Hospital Adauto Botelho, atualmente conhecido como Hospital Estadual de Atenção Clínica (HEAC), na cidade de Cariacica, em 1988, momento em que se realizou o I Curso de Acompanhamento Terapêutico no Estado, sendo o módulo prático realizado com usuários dos dois serviços. A experiência, no entanto, teve duração de apenas um ano, sendo possível somente a continuidade do trabalho pela via voluntária, devido a questões orçamentárias e políticas ${ }^{22}$.

A partir do processo de desinstitucionalização do Hospital Adauto Botelho e do surgimento dos Serviços Residenciais Terapêuticos em 2004, a prática do Acompanhamento Terapêutico foi sendo reinserida paulatinamente em tais setores, a partir de projetos de extensão vinculados aos cursos de psicologia e terapia ocupacional. Moreira ${ }^{23}$ aborda as experiências em Residências Terapêuticas no Espírito Santo e relata a inserção do Acompanhamento Terapêutico nos processos de reinserção social dos usuários dos Serviços Residenciais Terapêuticos, a partir da atividade realizada pelos estagiários do serviço.

Assim, dada a escassez de trabalhos no que tange ao acompanhante terapêutico no Espírito Santo, onde pouco se sabe sobre o profissional que exerce essa prática, se fazem necessários estudos e ampliação das divulgações da modalidade de tratamento em questão. Outra questão que se instala diz respeito à ausência de registro sobre o que é feito, como é feito e quais são os resultados obtidos a partir da prática. Assim, essa pesquisa se faz necessária para preencher essa lacuna no desenvolvimento do acompanhamento terapêutico da Grande Vitória.

A fim de possibilitar reflexões acerca de quem realiza essa prática e como ela é realizada, objetivouse conhecer quem são os acompanhantes terapêuticos do ES e identificar características das práticas de Acompanhamento Terapêutico no Estado.

\section{Metodologia}

A pesquisa foi realizada com dez profissionais que atuam na assistência em saúde mental da rede pública e/ou privada, e que utilizam ou utilizaram o AT como modalidade de atendimento. Nossa proposta foi trabalhar somente com acompanhantes terapêuticos de pacientes portadores de transtornos psiquiátricos.

Foram realizadas entrevistas parcialmente estruturadas ${ }^{24}$, orientadas mediante um roteiro. A primeira parte do roteiro continha questões referentes a características dos acompanhantes terapêuticos da Grande Vitória. O panorama traçado permitiu organizar a amostra dos participantes a partir dos Quadros 1 e 2. A segunda parte abarcava questionamentos referentes às práticas e dificuldades do Acompanhamento Terapêutico, e ao cotidiano de trabalho. Para apresentarmos as práticas descritas pelos participantes, agrupamos os resultados nas temáticas: "equipe de acompanhantes terapêuticos", "duração do AT", "setting terapêutico" e "buscar o acompanhado em casa".

Foi utilizada a técnica de amostragem não probabilística: "bola de neve", que consiste em solicitar, aos primeiros participantes contactados, que indiquem um participante em potencial ${ }^{25,26}$.

Os acompanhantes foram convidados a participar das entrevistas e informados sobre o objetivo da pesquisa, a liberdade para encerrar sua participação em qualquer momento, sem prejuízo, e sobre a garantia de sigilo absoluto da identidade, conforme estabelece a Resolução 196/96, do Conselho Nacional de Saúde. Todos os participantes assinaram o Termo de Consentimento Livre e Esclarecido. A presente pesquisa foi realizada em consonância com o Código de Ética Profissional do Psicólogo no que preconiza os aspectos éticos em estudos e pesquisas ${ }^{27}$.

As entrevistas foram gravadas em local, data e horário previamente agendados com os participantes, e, posteriormente, foram transcritas. Os dados colhidos foram analisados com base na Análise Temática proposta por Minayo ${ }^{28}$. Após a transcrição das entrevistas, foi feita a leitura do material de forma a agrupá-lo em temáticas. Tal procedimento foi realizado tendo por critério a frequência com que as temáticas apareciam, considerando aspectos pertinentes aos objetivos da pesquisa, e realização de recortes, como frases e palavras-chave, viabilizando a categorização dos dados. Posteriormente, foi realizada a transformação de dados brutos em síntese do conteúdo, com a classificação dos dados. Em seguida, foi realizada a interpretação dos dados obtidos ${ }^{28}$. 


\section{Resultados e discussões}

\section{Característica dos acompanhantes terapêuticos da Grande Vitória}

Tendo como objetivo conhecer as características do AT no estado, procuramos verificar quem são os acompanhantes terapêuticos. Desta forma, os resultados foram organizados em dois quadros. No Quadro 1, identificamos os dados pessoais e profissionais dos participantes.

Quadro 1. Dados pessoais e profissionais dos participantes.

\begin{tabular}{|l|l|l|l|l|}
\hline Participantes & \multicolumn{1}{|c|}{ Formação } & Sexo & \multicolumn{1}{|c|}{ Condição de atuação em AT } & \multicolumn{1}{|c|}{ Tempo de atuação em AT } \\
\hline 1 & Psicologia & F & Profissional & 6 anos \\
\hline 2 & Psicologia & F & Profissional & 6 anos \\
\hline 3 & Psicologia & F & Estudante & 2 anos \\
\hline 4 & Psicologia & F & Profissional & 21 anos \\
\hline 5 & Terapia ocupacional & F & Estudante & 8 a 9 meses \\
\hline 6 & Psicologia & F & Estudante & 2 anos \\
\hline 7 & Psicologia & M & Estudante & 3 anos e 6 meses \\
\hline 8 & Psicologia & F & Atuou como Estudante e como profissional & 4 anos \\
\hline 9 & Psicologia & F & Atuou como Estudante e como profissional & 1 ano e 6 meses \\
\hline 10 & Psicologia & M & Atuou como Estudante e como profissional & 4 anos \\
\hline
\end{tabular}

A partir do Quadro 1, verificamos que, dos dez participantes, nove fizeram a graduação em psicologia, e apenas um graduou-se em Terapia Ocupacional. No que diz respeito ao sexo do participante, somente dois são do sexo masculino. Tais resultados vêm corroborar a pesquisa de Carvalho ${ }^{15}$ na qual foi avaliado que a prática de AT era realizada, predominantemente, por mulheres graduadas em psicologia. Desta forma, apesar de a literatura apontar para a não-existência de uma formação acadêmica específica para a prática de tal atividade, podendo ser realizada por trabalhadores de saúde de funções variadas ${ }^{13,19,29}$, na Grande Vitória, os acompanhantes são, em sua maioria, do sexo feminino e possuem graduação em psicologia.

A inserção dos participantes no Acompanhamento Terapêutico se dá, em sua maioria, a partir de suas experiências como estudantes, nos estágios e projetos de extensão. Tal situação é semelhante à encontrada nos primeiros momentos do AT no Brasil, quando a realização dessa atividade era feita, inicialmente, por estudantes universitários (medicina, psicologia, enfermagem), que realizavam curso e Acompanhamento Terapêutico na própria clínica psiquiátrica ${ }^{8,16,17}$. Como exemplo, destacamos as falas de dois participantes:

“[...] foi meu primeiro estágio, eu estava no terceiro período." (P. 3)

"Eu tomei conhecimento do AT, primeiro pelo projeto de extensão que eu participava ainda como aluna de graduação." (P. 8)

Dentre os participantes, os dados mostram que alguns não continuaram a realizar o AT ao passarem para a condição de profissional, e a maioria não realiza tal atividade no momento da pesquisa. Ao serem questionados se estão realizando algum acompanhamento atualmente, somente dois participantes responderam que sim. Dos que responderam não, os participantes relataram que não estão realizando Acompanhamento Terapêutico, seja pela ausência de encaminhamentos ou 
por estarem impossibilitados no momento, devido ao envolvimento em outras atividades que não disponibilizam tempo.

“Não, não. Depois eu cessei, assim que eu formei [...] Aí eu abri um consultório particular e eu tinha preferido só deixar... ficar com os clientes no consultório em dias específicos e nos outros dias para poder ficar com as coisas do mestrado." (P. 7)

"Não é que eu abandonei, é que o meu momento não me dava possibilidade." (P. 9)

Carvalho ${ }^{15}$, ao pesquisar acerca do perfil do at, aponta que $71,9 \%$ dos acompanhantes terapêuticos realizam o AT como prática secundária, e atribui isso ao grau elevado de envolvimento pessoal que é exigido dos ats.

Quanto ao tempo de atuação em AT, o Quadro 1 aponta que existe uma diversidade no que diz ao período de experiência nesta modalidade. Desta maneira, verificamos a existência de acompanhante que atua há 21 anos, e que atua há menos de dois anos. Carvalho ${ }^{15}$ aponta que as diferentes gerações atuantes no AT podem contribuir para que atividades inovadoras e reflexões coexistam com a tradição.

Para melhor compreensão das características da atuação e formação dos acompanhantes terapêuticos na Grande Vitória, organizamos os resultados no Quadro 2.

Quadro 2. Características da atuação e formação dos ats na Grande Vitória.

\begin{tabular}{|l|l|l|l|l|}
\hline Participantes & $\begin{array}{l}\text { Atuação em serviço } \\
\text { Público/Privado }\end{array}$ & $\begin{array}{l}\text { Formação em } \\
\text { curso de AT }\end{array}$ & \multicolumn{1}{|c|}{$\begin{array}{c}\text { Abordagem teórica } \\
\text { no AT }\end{array}$} & \multicolumn{1}{|c|}{$\begin{array}{c}\text { Abordagem teórica } \\
\text { na prática psicológica }\end{array}$} \\
\hline 1 & Privado & Sim & Winnicott & Esquizoanálise \\
\hline 2 & Privado & Não & Não & Psicanálise \\
\hline 3 & Público & Não & Análise institucional & Análise institucional \\
\hline 4 & Privado & Sim & "Tudo o que for preciso" & Psicanálise lacaniana \\
\hline 5 & Público & Não & John Beneton* & -- \\
\hline 6 & Público & Não & Esquizoanálise & Esquizoanálise \\
\hline 7 & Privado & Não & Análise do Comportamento & Análise do Comportamento \\
\hline 8 & Privado & Não & "Não, não faço uso de nada não" & Psicologia Social \\
\hline 9 & Público & Não & Múltiplo & Esquizoanálise \\
\hline 10 & Privado & Não & Behaviorismo radical & Behaviorismo radical \\
\hline
\end{tabular}

"Autor que utiliza a saúde mental voltada para a Terapia Ocupacional

No que diz respeito à atuação no setor público ou privado, os resultados apontam que os estágios são realizados no serviço público, enquanto os profissionais, em sua maioria, atuam, ou atuaram, no setor privado. Verificamos assim, que, no serviço público na Grande Vitória, o AT se restringe à atuação dos estagiários advindos dos projetos de extensão vinculados a alguns cursos de Psicologia e Terapia Ocupacional da Grande Vitória, ou dos voluntários, o que confere um caráter temporário à atividade. Destacamos uma fala de um dos participantes para exemplificar:

“No serviço público, é mais feito por estagiários mesmo, né, porque não tem profissional de AT que faz isso, é, contratado pra isso né, sei que tem alguns estagiários que continuam fazendo essa prática, mas eu não vou saber falar pra você com propriedade como é que está indo." (P. 9)

Com base nos resultados, verificamos que o Acompanhamento Terapêutico não se apresenta de forma estruturada no serviço público, tornando-se difícil ofertá-lo aos usuários. Tal situação pode ser 
decorrente: do fato de as políticas públicas de saúde ainda não reconhecerem o acompanhante como parte da equipe ${ }^{23}$; da inexistência de leis para a contratação de acompanhantes terapêuticos no setor público, e da falta de uma normatização da prática do acompanhante ${ }^{7}$, o que dificulta a contratação de profissionais.

Verificamos também, conforme apresentado no Quadro 2, que, dentre os entrevistados, somente dois fizeram curso de AT.

"[...] foi mais na prática mesmo; é porque aqui não tem (curso)." (P. 9)

"Fiz um curso na FAESA, agora o ano [...]." (P. 1)

"[...] eu fiz um curso, um curso de 11 meses, no momento em que o AT chegou, começou no

ES. [...] na década de 90." (P. 4)

Em pesquisa realizada por Carvalho ${ }^{15}$ acerca do perfil dos acompanhantes terapêuticos no país, no que diz respeito à formação em AT, 53\% dos participantes declararam ter realizado ou estar realizando curso de formação em AT.

O Acompanhamento Terapêutico evoluiu muito desde as primeiras experiências nos anos 70 e, como resposta a tal evolução, algumas instituições passaram a oferecer curso de formação que contemplam os aspectos mais importantes do ofício de acompanhar. ${ }^{15}$ (p. 83)

Para a autora, os resultados vêm apontar uma solidificação do AT " [...] enquanto uma modalidade de tratamento e tem atraído profissionais dispostos a investir na própria formação"15 (p. 83). Na Grande Vitória, ao contrário, não há uma efetivação de instituições formadoras que venham a servir como referência aos acompanhantes terapêuticos, tornando-se um dificultador para a prática do AT no Estado.

Com base no Quadro 2, pode-se apontar, ainda, que a abordagem teórica utilizada pelos entrevistados na prática de AT é bem variada, sendo que dois participantes dizem não utilizar qualquer tipo de abordagem, não sendo possível identificar uma referência compartilhada pelos acompanhantes terapêuticos entrevistados. Tais resultados não corroboram a pesquisa de Carvalho ${ }^{15}$ que aponta que um grande número dos acompanhantes apresenta uma referência teórica, sendo a psicanálise a abordagem psicológica de maior abrangência na prática do AT, representando $69 \%$ da amostragem encontrada pela autora.

Verificamos também, com base nos resultados apresentados no Quadro 2, que a maior parte dos entrevistados, formados em psicologia, não utilizam, no AT, a mesma abordagem teórica que utilizam em sua prática profissional como psicólogos. Desta forma, os dados apontam que os acompanhantes terapêuticos fazem uso dos arcabouços teóricos que possam viabilizar a prática do AT, conforme exemplificado a seguir:

"[...] normalmente eu utilizo tudo que eu posso para fazer um melhor AT, até inclusive a própria psicanálise." (P. 4)

“Era uma prática, assim, bem múltipla. A gente olha, às vezes eu via alguma coisa da psicanálise [...] a gente fazia estágio na clínica em psicanálise. Então assim, alguma coisa na supervisão a gente pensava em psicanálise, ou então esquizoanálise, utilizava também corporal. Não tinha uma abordagem em si; era o que o campo demandava." (P. 9)

Tais resultados vão ao encontro da discussão de Abdalla, Batista e Batista ${ }^{30}$ de que o exercício da prática e conhecimento em psicologia, na atualidade, exige que o psicólogo desenvolva sua atuação profissional de forma a correlacionar seus objetivos, técnicas e teorias às necessidades sociais, isso faz com que o profissional, segundo Santos, Motta e $\operatorname{Dutra}^{31}$ (p. 382), "[...] busque uma articulação mais concreta entre a clínica e o social". Assim, uma nova prática pode ser construída a partir do contexto 
no qual o sujeito se insere. Além disso, Carvalho ${ }^{15}$ aponta que "[...] é desejável que ao se consolidar enquanto modalidade de tratamento o AT confirme sua natureza interdisciplinar e possa receber importantes contribuições de diferentes abordagens psicológicas ${ }^{15}$ (p. 81).

\section{Práticas de AT}

Ao buscarmos compreender as características das práticas de AT na Grande Vitória, encontramos as temáticas: "Equipe de acompanhantes terapêuticos", "Duração do AT", "Setting Terapêutico", "Buscar o Acompanhado em Casa" e "Afeto na prática do AT" como resultados significativos.

Sobre a "Equipe de acompanhantes terapêuticos", destacamos os seguintes aspectos: "atuação do entrevistado em equipes compostas por acompanhantes" e "características do trabalho em equipe". Verificamos, com base nos dados colhidos, que a maior parte dos profissionais entrevistados não estava inserida em equipes de acompanhantes terapêuticos. Ou seja, tal prática não se mostra comum na Grande Vitória, sendo priorizado o trabalho de um acompanhante terapêutico somente. Tal característica pode ser decorrente do desconhecimento da existência de outros acompanhantes ou da incompatibilidade de horário entre eles. A literatura, contudo, mostra que, em geral, o acompanhante faz parte de uma equipe multidisciplinar, composta, habitualmente, por: psiquiatra, o terapeuta individual, o terapeuta familiar e outros acompanhantes ${ }^{11,31}$.

No que diz respeito às "características do trabalho em equipe", verificamos que, nos espaços de estágio e extensão, o Acompanhamento Terapêutico é realizado em duplas de trabalho. Todavia, não encontramos relatos na literatura acerca do Acompanhamento Terapêutico em dupla, sendo uma característica do AT na Grande Vitória, em especial nos estágios oferecidos pelas instituições de Ensino Superior. Como podemos observar na fala que destacamos de uma das entrevistas:

"A gente trabalhava em dupla, não abria mão disso e a gente se dividia entre duas casas, que era uma casa feminina e uma masculina." (p. 3)

Outra característica importante do trabalho em equipe de acompanhantes na Grande Vitória, diz respeito às reuniões em que os mesmos participam para discutir o acompanhamento e os mecanismos a serem utilizados para lidar com a necessidade do acompanhado, desta forma priorizando o trabalho integrado.

Os participantes relatam, também, que, algumas vezes, a reunião se dava com a presença do acompanhado, e discutiam o que poderiam fazer. Segundo Reis Neto, Pinto e Oliveira ${ }^{17}$ :

É comum que a equipe de profissionais envolvida em um determinado caso estabeleça formas de discussão do andamento do trabalho, o que dá a essa equipe um caráter interdisciplinar. Além das reuniões de equipe geral nas quais se discute o caso em andamento, as equipes de AT podem também fazer reuniões de mini-equipe, que incluem somente os ats que acompanham determinado sujeito, ou mesmo optarem por supervisores de sua preferência para abordarem aspectos específicos do caso atendido. (p. 33)

Na temática "Duração do AT", constatamos, a partir dos relatos dos participantes, que existe um tempo de organização para a realização do AT, mas que o mesmo deve ser flexível, dependendo da programação para o encontro e, especialmente, da resposta do sujeito a esses encontros, sendo possível reduzir ou aumentar a duração, conforme a necessidade do acompanhado. Entretanto, os participantes pontuam que o tempo flexível não implica uma ausência de programação, ao contrário, é feito um contrato para a realização dos encontros, especialmente em relação ao seguinte.

“[...] não adianta você tá com o tempo programado, no acompanhamento terapêutico, tem que ter mais flexível." (P. 6) 
"Tem duração e hora, mas não tem uma duração padrão. Pode ser uma hora, duas horas, três horas, normalmente horas corridas, assim, não uma hora que é quebrada." (P. 4)

A flexibilidade do tempo, apontada pelos entrevistados, encontra-se em conformidade com a literatura, a qual indica que o período juntos, habitualmente, é bem maior que de uma psicoterapia, sendo possível durar duas horas ou mais, e se estender para mais de uma vez por semana, de acordo com a necessidade do acompanhado 6,11,15,17.

No que diz respeito ao "Setting Terapêutico", os participantes o definem como "[...] o espaço em que a pessoa será provocada pelo mundo, e que vai aprender a lidar com aquilo" (P. 8). Os resultados obtidos apontam para uma compreensão do setting como um espaço múltiplo de atuação, não tendo um espaço específico. Segundo os participantes, o espaço onde se encontravam era potencialmente terapêutico. Eles assinalam, ainda, a rua como um setting terapêutico.

"[...] mas muito mais na rua, no dia a dia da pessoa tentando trabalhar a dificuldade dela." (P. 1)

“[...] é difícil falar de acompanhamento terapêutico se não falar de saída né, enfim né, de permitir transitar né, coisas que são típicas de um cotidiano que você esbarra." (P. 8)

A literatura mostra que o setting terapêutico é bastante variável, sendo o contexto deste procedimento o espaço próprio do paciente, bem como as conjunturas nas quais foi estabelecida sua dificuldade ${ }^{11,13}$. Desta forma, a montagem do seu enquadre é bastante distinta da clínica clássica sendo, em geral, o horário, a duração e a localização bastante flexíveis ${ }^{15,32}$, saindo das instituições e começando a privilegiar o espaço social e de circulação pública, ainda que o público se restrinja ao desejo do paciente ou a uma residência ${ }^{33}$.

Os participantes relatam que "buscar o acompanhado em casa" é uma característica da prática, sendo que o encontro com o paciente se inicia na residência deste. "Não encontra a pessoa na rua, por exemplo, não sei se é isso que você tá perguntando. Você vai até a casa da pessoa, faz um contato, você é recebido, você é recebido na casa da pessoa" (P. 8).

Conforme a literatura, por ser indicado como uma clínica que acontece no cotidiano, o Acompanhamento Terapêutico irá se desenvolver em ambientes que fazem parte da vida do paciente; desta maneira, é muito comum o acompanhante terapêutico ir até a casa do paciente para, então, saírem, ou na porta do Hospital Dia, escola etc. ${ }^{11,15}$.

A temática "Afeto na prática do AT" foi obtida a partir de um relato de caso, e, apesar de ter sido mencionada, somente uma vez, foi avaliada como significativa. Os resultados apontam que o afeto é importante para a relação no Acompanhamento Terapêutico, todavia, se faz necessário um limite no afeto, pois não se trata de uma relação de amizade, conforme podemos exemplificar:

"A gente sempre enfatiza que existe um limite aí nesse afeto, que nós não somos amigos. Porque se não o acompanhamento terapêutico e todo o objetivo do trabalho se vai. Mas a gente tinha um envolvimento afetivo e isso se tornou muito evidente naquele momento e aí a gente começou a chorar junto com a usuária." (P. 3)

Ainda que em alguns momentos a relação entre acompanhante e acompanhado parecesse ser de amizade: "[...] o acompanhamento tem uma relação de assimetria do ponto de vista vincular; ou seja, não poderá estabelecer laços afetivos fortes, de natureza pessoal com o paciente, visto que sua relação tem uma função terapêutica"13 (p. 63). Barreto ${ }^{20}$ pontua que o conceito de simetria refere-se a indivíduos que estejam em um mesmo nível, entretanto, isso não implica a ausência de discriminação e diferenças entre eles. Assim, a preocupação do at com uma relação de assimetria implica um caráter de submissão entre acompanhante e acompanhado. Desta forma, Barreto ${ }^{20}$ pontua que " [...] no AT existe uma singularidade na amizade ou no sentimento de solidariedade que é dado pela tarefa que 
define o encontro" (p. 193). Conforme o autor, a amizade no AT possibilita, ao acompanhado, seu desenvolvimento psíquico. Segundo Lancetti ${ }^{34}$ (p.25-6), "[...] o acompanhante em sua intimidade amigável pode conectar ao mundo, realizar agenciamentos", desta maneira, a amizade é terapêutica por aliar-se à produção de um estilo de vida que objetiva transitar em mundos inacessíveis.

\section{Considerações finais}

A pesquisa alcançou os objetivos desejados ao compreender quem são os acompanhantes e quais as características da prática do Acompanhamento Terapêutico na Grande Vitória. Apesar disso, verificou-se que ainda se fala muito pouco do AT, tanto dentro das universidades quanto em eventos realizados na Grande Vitória. Associando a isso a precariedade de cursos de AT e a inexistência de leis que viabilizem a normatização da prática de Acompanhamento Terapêutico, torna-se difícil tanto a divulgação quanto a realização da prática. Assim, chegamos à conclusão de que o AT parece se limitar à presença dos estagiários nos serviços públicos e a uma prática secundária exercida por poucos profissionais de nível Superior nos serviços privados. Conclui-se, também, que o AT possui um caráter de coadjuvante ao tratamento, e não como parte importante da rede de assistência em saúde mental no Estado.

Além disso, a inexistência de cursos e de direcionamento teórico corrobora para que os acompanhantes não possuam uma referência da prática, seja para aprendizado, seja para discussões. Apesar das dificuldades, existem esforços para a realização do Acompanhamento Terapêutico na Grande Vitória, e podemos perceber algumas características concernentes à atuação nesta região, como: uma maior realização do AT por estagiários, geralmente em dupla, a importância do setting terapêutico, e uma maior flexibilidade no tempo de trabalho.

Os resultados apontam a necessidade de realização de estudos acerca do Acompanhamento Terapêutico na Grande Vitória, visto que a problematização e divulgação da relevância e eficácia do AT para a ampliação da saúde mental possibilitaria uma maior discussão e desenvolvimento dessa prática na Grande Vitória.

\section{Agradecimentos}

Este artigo foi elaborado com base na dissertação de mestrado entitulada "Acompanhamento Terapêutico: concepções e significados nas práticas em saúde mental em Vitória". Agradecemos à Coordenação de Aperfeiçoamento de Pessoal de Ensino Superior ( CAPES) pelo financiamento a essa pesquisa, viabilizando assim, a execução da mesma.

\section{Colaboradores}

As autoras trabalharam juntas na análise do material investigado. Kelly Guimarães Tristão foi responsável pela redação do artigo e Luzianne Zacché Avellar pela sua orientação e revisão. 


\section{Referências}

1. Sadigursky D, Tavares JL. Algumas considerações sobre o processo de desinstitucionalização. Rev Latino-Am Enferm. 1998; 6(2):23-7.

2. Ministério da Saúde. Secretaria-Executiva. Secretaria de Atenção à Saúde. Legislação em saúde mental: 1990-2004 [Internet]. 5a ed. Brasília (DF): MS; 2004 [acesso 2011 Ago 2]. Disponível em: http://bvsms.saude.gov.br/bvs/publicacoes/legislacao_mental.pdf

3. Ministério da Saúde. Secretaria de Atenção à Saúde. Departamento de Ações Programáticas Estratégicas. Manual do Programa "De volta pra casa". Brasília (DF): MS; 2003.

4. Ministério da Saúde. Secretaria de Atenção à Saúde. DAPE. Coordenação Geral de Saúde Mental. Reforma psiquiátrica e política de saúde mental no Brasil. Documento apresentado à Conferência Regional de Reforma dos Serviços de Saúde Mental: 15 anos depois de Caracas [Internet]. Brasília (DF): MS; 2005 [ acesso 2011 Ago 2]. Disponível em: http://bvsms.saude.gov.br/bvs/publicacoes/relatorio15_anos_caracas.pdf

5. Amorim AKMA, Dimenstein M. Desinstitucionalização em saúde mental e práticas de cuidado no contexto do serviço residencial terapêutico. Cienc Saude Colet. 2009; 14(1):195-204.

6. Pitia ACA, Furegato ARF. O Acompanhamento Terapêutico (AT): dispositivo de atenção psicossocial em saúde mental. Interface (Botucatu). 2009; 13(30):67-77.

7. Marinho, MD. Acompanhamento terapêutico: caminhos clínicos, políticos e sociais para a consolidação da Reforma Psiquiátrica brasileira [dissertação]. São Paulo (SP): Escola de Enfermagem, Universidade de São Paulo; 2009.

8. Silva AST, Silva RN. A emergência do acompanhamento terapêutico e as políticas de saúde mental. Psicol Cienc Prof. 2006; 2:210-21.

9. Almeida BHM. Que Paris é esse? Fragmentos clínicos. In: Equipe de Acompanhantes terapêuticos do Instituto A Casa, organizador. Textos, texturas e tessituras no Acompanhamento Terapêutico. São Paulo: Hucitec; 2006. p. 79-103.

10. Ayub P. Do amigo qualificado ao Acompanhante Terapêutico. Infanto Rev Neuropsiquiatr Inf Adolesc. 1996; 4(2):37-40.

11. Mauer SK, Resnizky S. Acompanhantes terapêuticos e pacientes psicóticos: manual introdutório a uma estratégia clínica. Campinas: Papirus; 1987.

12. Coutinho MF, Estellita-Lins C, Oliveira V. Clínica ampliada em saúde mental: cuidar e suposição de saber no acompanhamento terapêutico. Cienc Saude Colet. 2009; 18(1):205-15.

13. Pitiá ACA., Santos MA. Acompanhamento terapêutico: a construção de uma estratégia clínica. São Paulo: Vetor; 2005.

14. Araujo F. Do amigo qualificado à política da amizade. Estilos Clin. 2005; 10(19):85-105.

15. Carvalho SS. Acompanhamento terapêutico: que clínica é essa? São Paulo: Annablume; 2004.

16. Ibrahim C. Do louco à loucura: percurso do auxiliar psiquiátrico no Rio de Janeiro. In: Equipe de Acompanhantes Terapêuticos A Casa, organizador. A Rua como espaço clínico: Acompanhamento Terapêutico. São Paulo: Escuta; 1991. p. 43-9.

17. Reis Neto RO, Pinto AC, Oliveira LGA. Acompanhamento terapêutico: História, clínica e saber. Psicol Cienc Prof. 2011; 31(1):30-9.

18. Silva ALB, Silva MBPS. Acompanhamento terapêutico: técnicas e ética. In: Equipe de Acompanhantes Terapêuticos do Instituto A Casa, organizador. Crise e cidade: acompanhamento terapêutico. São Paulo: Educ; 2000. p. 219-31. 
19. Simões CHD. A produção científica sobre acompanhamento terapêutico no Brasil de 1960 a 2003: uma análise crítica [dissertação]. Campinas (SP): Faculdade de Ciências Médicas, Universidade Estadual de Campinas; 2005.

20. Barreto KD. Ética e técnica no Acompanhamento Terapêutico: andança com Dom Quixote e Sancho Pança. São Paulo: Unimarco Editora; 1998.

21. Azevedo T, Dimenstein M. O acompanhamento terapêutico no cuidado em saúde mental. Estud. Pesqui. Psicol. 2008; 8(3):658-71.

22. Benevides LLMG. A função de publicização do acompanhamento terapêutico na clínica: o contexto, o texto e o foratexto do AT [dissertação]. Rio de Janeiro: Universidade Federal Fluminense; 2007.

23. Moreira MIB, organizador. Loucura e cidade: potencializando novos territórios existenciais. Vitória: GM; 2008.

24. Gil AC. Como elaborar projetos de pesquisa. 4a ed. São Paulo: Atlas; 2002.

25. Biernacki $P$, Waldorf $D$. Snowball sampling: problems and techniques of chain referral sampling. Sociol Meth. 1981; 10:141-63.

26. Becker HS. Métodos de pesquisa em Ciências Sociais. São Paulo: Hucitec; 1993.

27. Conselho Federal de Psicologia. Código de ética profissional do Psicólogo. Brasília, publ. VIII Plenário do Conselho Federal de Psicologia. Brasília (DF); 2005.

28. Minayo MC, organizador. Pesquisa social: teoria, método e criatividade. Petrópolis: Vozes; 2002.

29. Berger E. Acompanhamento terapêutico: invenções. In: Equipe de Acompanhantes Terapêuticos de A Casa, organizador. Crise e cidade: acompanhamento terapêutico. São Paulo: Educ; 1997. p. 71-82.

30. Abdalla IG, Batista SH, Batista NA. Desafios do ensino de psicologia clínica em cursos de psicologia. Psicol Cienc Prof. 2008; 28(4):806-19.

31. Santos LG, Motta JM, Dutra MCB. Acompanhamento terapêutico e a clínica das psicoses. Rev Latinoam Psicopatol Fundam. 2005; 8(3):497-514.

32. Coelho CFM. Convivendo com Miguel e Mônica: uma proposta de Acompanhamento Terapêutico de crianças autistas [dissertação]. Brasília (DF): Instituto de Psicologia, Universidade de Brasília; 2007.

33. Caiaffa RA. O acompanhamento terapêutico e a rua. In: Equipe de Acompanhamento Terapêutico do Hospital-Dia A Casa, organizador. A rua como espaço clínico. São Paulo: Escuta; 1991. p. 93-100.

34. Lancetti A. A amizade e o acompanhamento terapêutico. In: Equipe de acompanhantes terapêuticos A Casa, organizadores. Textos, texturas e tessituras: no acompanhamento terapêutico. São Paulo: Hucitec; 2006. p. 21-6. 
Tristão KG, Avellar LZ. Acompañantes terapéuticos en el area metropolitana de Vitória, Espírito Santo, Brasil: ¿quiénes son y qué hacen? Interface (Botucatu). 2014; 18(50):533-44.

El Acompañamiento Terapéutico (AT) es una herramienta de ampliación y articulación de la red de salud mental. nuestro objetivo fue conocer quiénes son los acompañantes terapéuticos (ats) de Vitória/ Estado de Espírito Santo y las características de esa práctica. Se realizaron diez entrevistas parcialmente estructuradas con profesionales que utilizan, o utilizaron, el Acompañamiento Terapéutico en la red pública y/o privada. Los datos se analizaron a partir del Análisis Temático. Los resultados señalan que los acompañantes terapéuticos son, en su mayoría, estudiantes de psicología del sexo femenino, de abordajes teóricos variados y cuya formación en Acompañamiento Terapéutico no se realiza a partir de curso de esa área. La práctica de AT investigada se caracteriza por la poca inserción en equipos de acompañantes, actuación en pareja, flexibilidad de tiempo, intervenciones realizadas en la calle y afecto.

Palabras clave: Salud mental. Desinstitucionalización. Servicios de salud y Acompañamiento Terapéutico.

Recebido em 10/09/13. Aprovado em 17/02/14. 